\title{
Positron emission tomography agent 2-deoxy-2-[18F]fluoro-D- glucose has a therapeutic potential in breast cancer
}

\author{
Renee M Moadel ${ }^{1}$, Andrew V Nguyen², Elaine Y Lin ${ }^{3}$, Ping Lu ${ }^{1}$, Joseph Mani ${ }^{1}$, M Donald Blaufox ${ }^{1}$, \\ Jeffrey W Pollard ${ }^{3}$ and Ekaterina Dadachova ${ }^{1}$
}

1Department of Nuclear Medicine, Albert Einstein College of Medicine of Yeshiva University, Bronx, New York, USA
2Department of Microbiology and Immunology, Albert Einstein College of Medicine of Yeshiva University, Bronx, New York, USA
3Department of Developmental and Molecular Biology, Albert Einstein College of Medicine, Bronx, New York, USA

Corresponding author: Ekaterina Dadachova (e-mail: edadacho@aecom.yu.edu)

Received: 8 Apr 2003 Revisions requested: 30 Jun 2003 Revisions received: 8 Jul 2003 Accepted: 17 Jul 2003 Published: 22 Aug 2003

Breast Cancer Res 2003, 5:R199-R205 (DOI 10.1186/bcr643)

(C) 2003 Moadel et al., licensee BioMed Central Ltd (Print ISSN 1465-5411; Online ISSN 1465-542X). This is an Open Access article: verbatim copying and redistribution of this article are permitted in all media for any purpose, provided this notice is preserved along with the article's original URL.

See related Commentary: http://breast-cancer-research.com/content/5/6/329

\begin{abstract}
Background: Novel approaches are needed for breast cancer patients in whom standard therapy is not effective. 2-Deoxy-2[18F]fluoro-D-glucose (18F-FDG) was evaluated as a potential radiomolecular therapy agent in breast cancer animal models and, retrospectively, in patients with metastatic breast cancer.

Methods: Polyoma middle T antigen (PyMT) and mouse mammary tumor virus-NeuT transgenic mice with tumors $0.5-1 \mathrm{~cm}$ in diameter were imaged with ${ }^{18} \mathrm{~F}-\mathrm{FDG}$, and tumor to liver ratios (TLRs) were calculated. The radiotoxicity of ${ }^{18} \mathrm{~F}-\mathrm{FDG}$ administration was determined in healthy mice. PyMT mice with small $(0.15-0.17 \mathrm{~cm})$ and large (more than $1 \mathrm{~cm})$ tumors were treated with $2-4 \mathrm{mCi}$ of $18 \mathrm{~F}-\mathrm{FDG}$, and control $\mathrm{C} 3 \mathrm{H} / \mathrm{B} 6$ mice with $3 \mathrm{mCi}$ of ${ }^{18} \mathrm{~F}-\mathrm{FDG}$. At 10 days after treatment the tumors and control mammary glands were analyzed for the presence of apoptotic and necrotic cells. Five patients with breast cancer and metastatic disease were evaluated and standardized uptake values (SUVs) in tumors, maximum tolerated dose, and the doses to the tumor were calculated.
\end{abstract}

\begin{abstract}
Results: Doses up to $5 \mathrm{mCi}$ proved to be non-radiotoxic to normal organs. The ${ }^{18} \mathrm{~F}-\mathrm{FDG}$ uptake in mouse tumors showed an average TLR of 1.6. The treatment of mice resulted in apoptotic cell death in the small tumors. Cell death through the necrotic pathway was seen in large tumors, and was accompanied by tumor fragmentation and infiltration with leukocytes. Normal mammary tissues were not damaged. A human ${ }^{18} \mathrm{~F}-\mathrm{FDG}$ dose delivering $200 \mathrm{rad}$ to the red marrow (less than $5 \%$ damage) was calculated to be $4.76 \mathrm{Ci}$ for a $70 \mathrm{~kg}$ woman, and the dose to the tumors was calculated to be 220, 1100 and 2200 rad for SUVs of 1,5 and 10, respectively.
\end{abstract}

Conclusion: We have shown that positrons delivered by ${ }^{18} \mathrm{~F}-\mathrm{FDG}$ to mammary tumors have a tumoricidal effect on cancer cells. The study of breast cancer patients suggests that the tumor and normal organ dosimetry of ${ }^{18} \mathrm{~F}-\mathrm{FDG}$ makes it suitable for therapy of this malignancy.

Keywords: breast cancer, 2-deoxy-2-[18F]fluoro-D-glucose, mouse models, positrons, therapy

\section{Introduction}

Breast cancer remains a major cause of cancer death in women in the developed world. Novel therapeutic modalities are needed for those patients in whom chemotherapy, hormonal treatment and external radiation therapy are ineffective. 2-Deoxy-2-[18F]fluoro-D-glucose (18F-FDG) is widely used in positron emission tomography (PET) for the evaluation of patients with tumors $[1,2]$. It was shown by
Warburg in 1930 that glucose is actively utilized by tumor cells [3]. In recent years the use of ${ }^{18} \mathrm{~F}$-FDG-PET has become well established in the diagnosis of breast cancer, because many breast cancers demonstrate high avidity for ${ }^{18} \mathrm{~F}$-FDG [4], which is an analogue of glucose in which the hydroxy group in the 2 position has been replaced with a fluorine atom. ${ }^{18} \mathrm{~F}-\mathrm{FDG}$ is taken up by the cells and phosphorylated by hexokinase to ${ }^{18} \mathrm{~F}-\mathrm{FDG}-6$ -

${ }^{18} \mathrm{~F}-\mathrm{FDG}=2$-deoxy-2-[18F]fluoro-D-glucose; H\&E = haematoxylin and eosin; MMTV = mouse mammary tumor virus; PET = positron emission tomography; PyMT = polyoma middle T antigen; SUV = standardized uptake value; TLR = tumor to liver ratio. 
phosphate. Because ${ }^{18} \mathrm{~F}-\mathrm{FDG}$ is not a substrate for glycolysis and does not undergo further metabolism, it remains trapped in the cell [5].

${ }^{18} \mathrm{~F}$ emits positrons with an average energy of $0.250 \mathrm{MeV}$ and abundance of $96 \%$. Positrons lose their kinetic energy in the tissue in the same manner as electrons, thereby damaging tissue. This is followed by annihilation, which results in the emission of two photons with an energy of $511 \mathrm{keV}$ in opposite directions. Although the potential of electrons to kill cancer cells through the loss of their kinetic energy has been made use of in radionuclide cancer treatment for more than 50 years (since the introduction of therapy of thyroid cancer with ${ }^{131}$ [ [6]), the therapeutic potential of positrons has remained unexplored. Theoretically, positrons should kill cancer cells during the loss of kinetic energy in the same manner as electrons.

Here we evaluate, for the first time to our knowledge, the potential of ${ }^{18} \mathrm{~F}$-FDG as a positron-emitting agent for the radiomolecular therapy of breast cancer in breast cancer animal models and, retrospectively, in patients with metastatic breast cancer.

\section{Materials and methods Animals}

All procedures involving mice were conducted in accordance with the National Institutes of Health regulations concerning the use and care of experimental animals. The study of mice was approved by the Albert Einstein College of Medicine Animal Use Committee. Transgenic mice expressing the polyoma middle Tantigen (PyMT) in the mammary epithelium under the control of mouse mammary tumor virus (MMTV) long terminal repeat were provided by Dr WJ Muller (McMaster University, Ontario, Canada) and then bred in our institution. At the age of 10 weeks these mice have multiple mammary tumors $0.15-0.17 \mathrm{~cm}$ in diameter. In mice older than 18 weeks the tumors are more than $1 \mathrm{~cm}$ in diameter. MMTV-NeuT mice [7], which carry erbB-2 $(\mathrm{Neu})$, one of the better known human breast cancer oncogenes, were purchased from Jackson Laboratories. MMTV$\mathrm{NeuT}$ mice were obtained as retired breeders and some of them developed mammary tumors at the age of 5 months, whereas others remained-tumor free until 6-7 months of age. C3H/B6 female mice lacking the PyMT transgene were used as healthy controls in therapy experiments.

\section{Imaging of mice with ${ }^{18} \mathrm{~F}-\mathrm{FDG}$}

PyMT mice older than 18 weeks, with tumors more than $1 \mathrm{~cm}$ in diameter, MMTV-NeuT tumor-bearing mice $(0.5-1 \mathrm{~cm}$ in diameter) and tumor-free MMTV-NeuT mice were fasted for 4 hours before the injection of radiotracer. Three animals were used in each group. They were anesthetized with a mixture of $125 \mathrm{mg} / \mathrm{kg}$ ketamine and $10 \mathrm{mg} / \mathrm{kg}$ xylazine. An injection of $0.5-2.0 \mathrm{mCi} 18 \mathrm{~F}-\mathrm{FDG}$ while anesthetized for an uptake period of 1 hour. A scan was performed on a dedicated PET scanner CPET (Philips). Scans (6 min emission and $45 \mathrm{~s}$ transmission) were obtained. The data were acquired with a zoom of 2 and a slice thickness of $2 \mathrm{~mm}$. Images were reconstructed with an iterative reconstruction algorithm and corrected for attenuation. To reduce volume averaging, a small round region of interest 12 pixels in size was drawn in the center of the tumor and in the center of normal liver. The diameter of the region was $7 \mathrm{~mm}$. The tumor to liver ratios (TLRs) were calculated by the formula TLR $=$ counts per pixel in tumor divided by counts per pixel in liver.

\section{Radiotoxicity studies of ${ }^{18} \mathrm{~F}-\mathrm{FDG}$ in healthy mice}

After a 4-hour fast, 2 groups of BALB/c mice were treated i.p. with the following doses of $18 \mathrm{~F}-\mathrm{FDG}$ : group 1 (three mice), $2.5 \mathrm{mCi}$; group 2 (three mice), $5 \mathrm{mCi}$; group 3 (three mice), left untreated for control. The mice were monitored for changes in behavior and body weight for 1 month, after which they were killed; their heart, brain, liver, kidneys, bladder, and bone marrow were removed, fixed in buffered formalin, sectioned, stained with hematoxylin and eosin (H\&E), and analyzed histologically.

\section{Treatment of PyMT mice with ${ }^{18} \mathrm{~F}-\mathrm{FDG}$}

After a 4-hour fast, three groups of mice were treated i.p. with the following doses of 18F-FDG: group 1 (five 10-week-old mice), 2-4 mCi; group 2 (three 22-week-old mice), $2 \mathrm{mCi}$; group 3 (two C3H/B6 mice), $3 \mathrm{mCi}$ to assess radiation damage to healthy breast tissue. Three 10-weekold and two 22-week-old PyMT mice served as untreated controls. At 10 days after treatment, mice were killed. In younger mice, the right abdominal mammary glands were removed for whole mount preparation as described [8], then fixed in buffered formalin and sectioned. In older mice, the tumors were removed and processed as above. Some sections were stained with $\mathrm{H} \& \mathrm{E}$; others were analyzed for the presence of apoptotic and necrotic cells.

\section{Apoptosis and necrosis detection}

The detection of apoptotic and necrotic cells in the tumors was performed with an Apoptag Plus ${ }^{\circledR}$ apoptosis detection kit (Serologicals) in accordance with the manufacturer's instructions. In brief, 3'-OH termini of DNA fragments, which are the hallmark of apoptosis, were labeled with digoxigenin-modified nucleotides by terminal deoxynucleotidyl transferase. This enzyme selectively detects apoptotic over necrotic cells. The labeled DNA was detected with an anti-digoxigenin antibody, and detection was performed with a chromagen: apoptotic cells were stained brown, and areas of necrosis were stained yellow.

\section{${ }^{18} \mathrm{~F}$-FDG-PET in breast cancer patients with metastatic disease}

Approval was obtained from the Albert Einstein College of Medicine Cancer Center Protocol Review Committee 
and the Montefiore Medical Center Institutional Review Board. Retrospectively, five consecutive patients with breast cancer and metastatic disease shown on ${ }^{18}$ F-FDG-PET scanning were evaluated. After more than 4 hours of fasting, the patients were administered $3.5 \mathrm{mCi}$ of $18 \mathrm{~F}-F D G$, and rested during an uptake period of $45 \mathrm{~min}$. The patients then underwent a whole-body scan on the CPET scanner. The scanning protocol consisted of 6 min of emission and two rotations of a ${ }^{137} \mathrm{Cs}$ source for transmission per bed position, and approximately six bed positions. Images were corrected for attenuation and reconstructed with the iterative method. To reduce volume averaging, a small round region of interest 12 pixels in size was drawn in the center of the tumor and in the center of normal liver. The diameter of the region was $14 \mathrm{~mm}$. Standardized uptake values (SUVs) were calculated for all regions of interest by the formula SUV $=$ (activity in tissue $[\mathrm{mCi} / \mathrm{g}]$ ) divided by (injected activity $[\mathrm{mCi}] /$ body weight $[\mathrm{g}]$ ).

TLRs were calculated by the formula TLR $=$ SUV of tumor divided by SUV of liver.

The dose-limiting organ for therapy with ${ }^{18} \mathrm{~F}-\mathrm{FDG}$ is the bone marrow. The activity of $18 \mathrm{~F}-\mathrm{FDG}$ that will deliver doses of $200 \mathrm{rad}$ to the red marrow (less than 5\% damage in 5 years) [9] and also 300 rad were calculated using the Medical Internal Radionuclide Dosimetry formalism. A dose of $\mathbf{3 0 0}$ rad was considered because it causes acceptable and manageable hematologic toxicity in selected patients [9]. The subsequent doses delivered to 18 F-FDG-avid tumors were calculated.

\section{Results \\ Uptake of ${ }^{18} \mathrm{~F}-\mathrm{FDG}$ in mammary tumors of PyMT and MMTV-neuT mice}

Coronal PET images of PyMT and MMTV-neuT mice injected with ${ }^{18} \mathrm{~F}-\mathrm{FDG}$ are presented in Figure 1. Slices ( $2 \mathrm{~mm}$ thickness) with the highest activity in the tumor were chosen. There was significant uptake of $18 \mathrm{~F}-\mathrm{FDG}$ by the tumors in PyMT (Fig. 1a,b) and MMTV-neuT mice (Fig. 1c). The tumor uptake was uniform. TLRs were (mean \pm SD) $1.6 \pm 0.4$ and 1.6 \pm 0.1 in MMTV-neuT and PyMT mice, respectively. No abnormal uptake was seen in a tumor-free mouse (Fig. 1d). As ${ }^{18} \mathrm{~F}-\mathrm{FDG}$ is normally excreted in the urine, bladder activity was visible in all mice. The avidity of tumors for ${ }^{18} \mathrm{~F}-\mathrm{FDG}$ provided an impetus for investigation of the therapeutic effect of ${ }^{18} \mathrm{~F}-\mathrm{FDG}$ on mammary tumors in mice.

\section{Lack of radiotoxicity of ${ }^{18} \mathrm{~F}-\mathrm{FDG}$ in normal mice}

Treatment of healthy mice with doses of up to $5 \mathrm{mCi}$ ${ }^{18} \mathrm{~F}-\mathrm{FDG}$ caused no damage in major organs (as determined by histological examination) including bone marrow, which is a dose-limiting organ in patients (results not shown).
Toleration of treatment of PyMT mice with ${ }^{18} \mathrm{~F}-\mathrm{FDG}$

PyMT mice treated with 2-4 mCi 18 F-FDG were observed for 10 days for obvious signs of radiation toxicity. At $24 \mathrm{~h}$ after injection no radioactivity was detected in mice because of the excretion and complete radioactive decay of the relatively short-lived isotope ${ }^{18} \mathrm{~F}$ (half-life $110 \mathrm{~min}$ ). No changes in eating and drinking habits, urine and fecal excretion, or body weight were seen.

\section{Damage to the tumors by ${ }^{18}$ F-FDG}

Figure 2 shows microscopic images of small and large tumors from PyMT mice. The small $(0.15-0.17 \mathrm{~cm}$ diameter) tumors from 10-week-old mice treated with ${ }^{18} \mathrm{~F}-\mathrm{FDG}$ had numerous apoptotic cells clearly present in the center of the treated tumors (Fig. 2a) that were not detected in untreated tumors (Fig. 2b). Overall, $4 \pm 1 \%$ of cells in the treated small tumors were apoptotic, in comparison with less than $1 \%$ in untreated tumors $(P<0.05)$. No apoptosis or necrosis was detected in the healthy mammary glands of $\mathrm{C} 3 \mathrm{H} / \mathrm{B} 6$ mice treated with $3 \mathrm{mCi}$ of ${ }^{18} \mathrm{~F}-\mathrm{FDG}$ (Fig. 2c). ${ }_{18} \mathrm{~F}-\mathrm{FDG}$ treatment also caused much more cell death through the necrotic pathway in large (more than $1 \mathrm{~cm}$ ) tumors in 22-week-old mice than occurred in untreated tumors (Fig. 2d,e). In the treated tumors, the areas occupied by necrotic cells were stained brown-yellow (Fig. 2d), as opposed to the sheets of bluish tumor cells in untreated controls (Fig. 2e). Necrotic areas constituted $14 \%$ of the tumor volume in 22 -week-old mice. Some apoptotic cells were also visible at the rim of the necrotic area.

Figure 2f,g displays H\&E-stained large tumors from 22-week-old PyMT mice. Tumors that had been treated with 18 F-FDG were bloody when sectioned, which suggests resorption. This observation was confirmed by heavy infiltration of leukocytes in the H\&E-stained section (Fig. 2f). Furthermore, the sections of the tumors treated with ${ }^{18} \mathrm{~F}-\mathrm{FDG}$ showed a loss of coherence of the tumor cells with breaks in the epithelial sheets (Fig. 2f) as opposed to solid sheets of tumor cells found in the untreated controls (Fig. $2 \mathrm{~g}$ ).

\section{${ }^{18} \mathrm{~F}-\mathrm{FDG}-\mathrm{PET}$ in breast cancer patients with metastatic disease}

Table 1 summarizes the SUVs for metastatic tumors, SUVs for normal liver and TLRs in patients with metastatic breast cancer imaged with ${ }^{18} \mathrm{~F}-\mathrm{FDG}$. ${ }^{18} \mathrm{~F}-\mathrm{FDG}$-avid metastatic breast cancer in five retrospectively studied patients showed an average TLR of $2.7 \pm 0.8$. Figure 3 presents a ${ }^{18} \mathrm{~F}-\mathrm{FDG}-\mathrm{PET}$ projection image of a patient with breast cancer, metastatic to the right lung. A left lung metastasis was also seen. Normal activity in the heart, liver, kidneys, bladder, and bowel was observed. It should be also noted that the primary breast cancer had previously been resected, and the residual normal non-lactating breast tissue did not display increased ${ }^{18}$ F-FDG uptake 


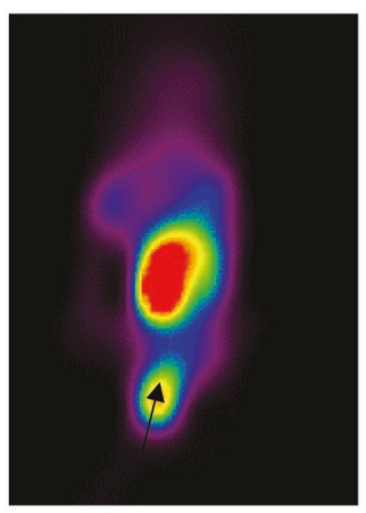

(a)

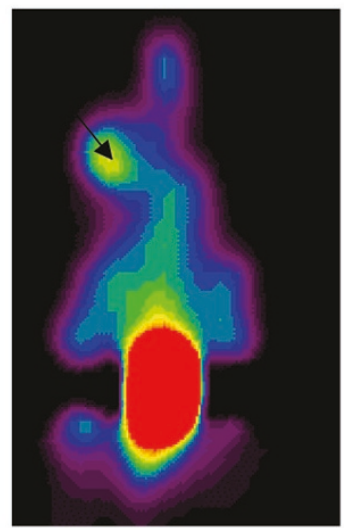

(c)

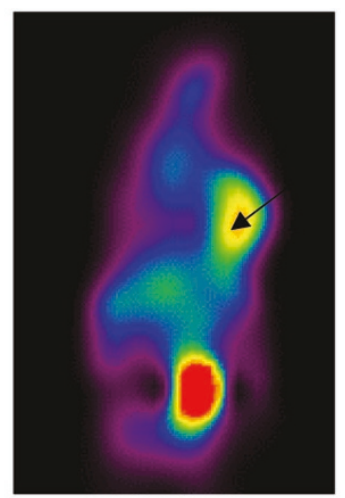

(b)

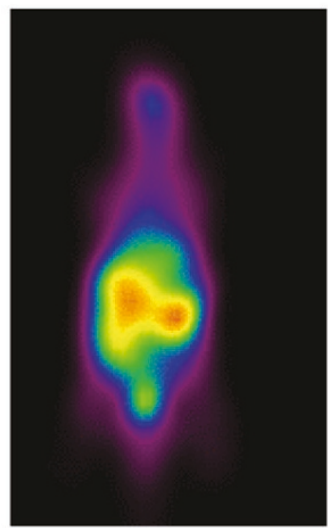

(d)

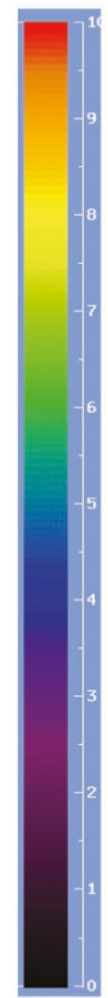

Coronal FDG-PET images of mice acquired $1 \mathrm{~h}$ after i.p. injection of ${ }^{18} \mathrm{~F}-\mathrm{FDG}$. Slices $(2 \mathrm{~mm}$ thick) with the highest activity in the tumor were chosen. All mice were lying on their backs with the heads pointing up. Tumors are marked with arrows. Because ${ }^{18} \mathrm{~F}$-FDG is normally excreted in the urine, bladder activity is visible in all mice. The highest radioactivity uptake shows as red. (a) PyMT mouse with an abdominal mammary tumor. (b) PyMT mouse with a thoracic mammary tumor. (c) MMTV-neuT mouse with a thoracic mammary tumor. (d) Tumor-free MMTV neuT mouse: no abnormal uptake is seen.

over the background. The SUV within a tumor was uniform, because our patients did not display areas of necrosis in the tumors. In patients with multiple tumors the SUVs varied from site to site. In patient 5 , the most intense SUV was 9.9 in the tumor with a diameter of $5 \mathrm{~cm}$, and the least intense SUV was 2.9 in the tumor with a diameter of $1.5 \mathrm{~cm}$. In patient 3 , the SUV was 5.8 in the tumor with dimensions $10 \mathrm{~cm} \times 6 \mathrm{~cm} \times 4.5 \mathrm{~cm}$, and the lowest SUV was 3.8 in the tumor with a diameter of $2 \mathrm{~cm}$.

The activity of ${ }^{18} \mathrm{~F}-\mathrm{FDG}$ to deliver 200 rad to the red marrow was calculated to be $4.76 \mathrm{Ci}$ for a $70 \mathrm{~kg}$ woman, and the subsequent tumor doses were calculated to be 220,1100 , and 2200 rad for SUVs of 1, 5, and 10, respectively. The activity of ${ }^{18} \mathrm{~F}-\mathrm{FDG}$ to deliver 300 rad to the red marrow was
1650, and 3300 rad for SUVs of 1, 5, and 10, respectively. These doses are in the tumoricidal range.

\section{Discussion}

We have reported the use of positrons for the treatment of malignancy. Theoretically, these positrons can kill cancer cells in the same manner as electrons. However, the cytocidal potential of positrons remains largely unexplored. Historically, owing to the early success of the therapy of thyroid cancer with ${ }^{131}$, which emits electrons, much of the further development of radiopharmaceuticals for cancer therapy has concentrated on electron-emitting radioisotopes. The only reported use of the cytocidal potential of positrons was described by Stoll and colleagues [10], who used a balloon filled with the positron-emitter ${ }^{8} \mathrm{Ga}$ for coronary artery brachytherapy to prevent restenosis. 

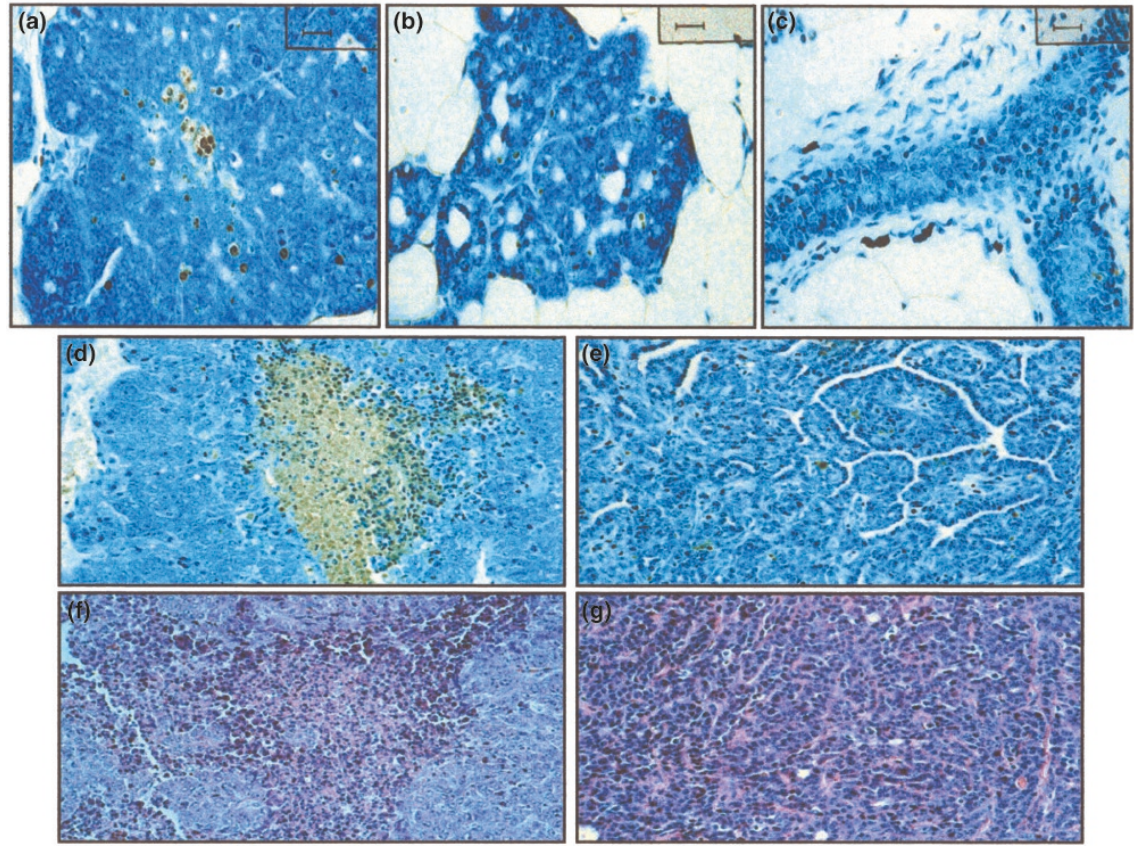

Apoptosis and necrosis caused by treatment with ${ }^{18} \mathrm{~F}-\mathrm{FDG}$ in mammary tumors in PyMT mice. Apoptotic and necrotic cells were detected with an Apoptag Plus apoptosis detection kit. (a) A treated tumor in a 10-week-old mouse has numerous apoptotic cells present (stained brown) in the center of the tumor. (b) An untreated tumor in a mouse of the same age has an insignificant number of apoptotic cells. (c) Healthy mammary glands of $\mathrm{C} 3 \mathrm{H} / \mathrm{B} 6$ mice treated with $3 \mathrm{mCi}$ of ${ }^{18} \mathrm{~F}$-FDG: no apoptotic or necrotic cells are present. (d) A treated tumor in a 22-week-old mouse shows extensive necrotic areas (stained brown-yellow); some apoptotic cells are also seen at the rim of the necrotic area. (e) An untreated tumor in a 22-week-old mouse. (f) An H\&E-stained treated tumor in a 22-week-old mouse: heavy infiltration by leukocytes and a loss of coherence of the tumor cells with breaks in the epithelial sheets are observed. (g) An untreated tumor in a mouse of the same age shows solid sheets of tumor cells. Original magnifications: $(\mathrm{a}-\mathrm{c}) \times 400 ;(\mathrm{d}-\mathrm{g}) \times 200$.

Table 1

Standardized uptake values (SUVs) for metastatic tumors and normal liver; and tumor to liver ratios (TLRs) in patients with metastatic breast cancer imaged with $3.5 \mathrm{mCi}$ of ${ }^{18} \mathrm{~F}-\mathrm{FDG}$

\begin{tabular}{lllll}
\hline \multirow{2}{*}{ Patient } & Diagnosis & \multicolumn{2}{c}{ SUV } \\
\cline { 3 - 5 } 1 & Metastasis to sub-carinal lymph node & Metastasis & Normal liver & TLR \\
2 & Metastasis to the left axilla & 5.3 & 2.8 & 2.89 \\
3 & Liver metastasis & 7.4 & 2.3 & 2.3 \\
4 & Metastasis to the right axilla & 5.8 & 2.1 & 2.36 \\
5 & Right lung metastasis & 5.3 & 2.3 & 3.6 \\
\hline
\end{tabular}

SUVs were calculated for all regions of interest by the formula SUV = (activity in tissue $[\mathrm{mCi} / \mathrm{g}] \mathrm{divided}$ by (injected activity [mCi]/body weight [g]). TLRs were calculated by the formula TLR $=$ SUV of tumor divided by SUV of liver.

Metabolic trapping of ${ }^{18} \mathrm{~F}-\mathrm{FDG}$ is an attractive mechanism for delivering radioactivity to tumors, because neoplastic cells have an enhanced rate of glucose utilization [11]. This mechanism has been used successfully in ${ }^{18} \mathrm{~F}-\mathrm{FDG}$ $\mathrm{PET}$, which is widely used in nuclear medicine for the diagnosis of oncological diseases. ${ }^{18} \mathrm{~F}-\mathrm{FDG}$ has the ability to remain in cancer cells with low efflux rates. With a physical half-life of almost 2 hours, ${ }^{18} \mathrm{~F}$ emits energetic positrons with high abundance $(96 \%)$ and a path length in tissue of about $0.1-0.2 \mathrm{~cm}$. These qualities make ${ }^{18} \mathrm{~F}-\mathrm{FDG}$ a potential candidate for investigation as an agent for the treatment of breast and other cancers. 
Figure 3

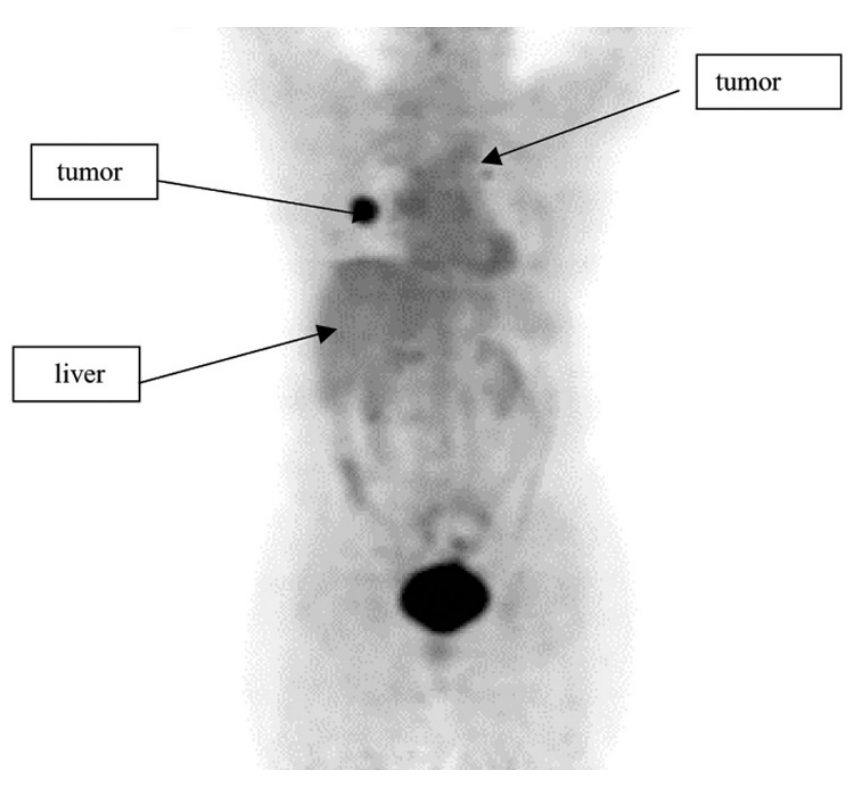

${ }^{18} \mathrm{~F}$-FDG-PET projection image of a patient with breast cancer metastatic to the right lung. A metastasis to the left lung is also visible. Normal activity is observed in the heart, liver, kidneys, bladder, and bowel. The primary breast cancer had previously been resected, and the residual normal non-lactating breast tissue did not display increased ${ }^{18} \mathrm{~F}$-FDG uptake over the background.

Our imaging experiments in two different mouse mammary cancer models (the PyMT model of murine mammary cancer and the MMTV NeuT model, which carries the erbB-2 human breast cancer oncogenes) showed that it is possible to use these models for the investigation in vivo of the tumoricidal properties of positrons, because tumor uptake was demonstrated. We observed apoptosis and necrosis in tumors treated with ${ }^{18} \mathrm{~F}-\mathrm{FDG}$; particulate ionizing radiation is known to cause cell death through both the apoptotic [12] and necrotic pathways [13,14]. In small tumors (0.15-0.17 cm in diameter) in PyMT mice treated with ${ }^{18} \mathrm{~F}-\mathrm{FDG}$, the prevalent mode of cell death was apoptosis, whereas in large tumors (more than $1 \mathrm{~cm}$ in diameter) the radiation induced widespread necrosis. A possible explanation for this difference is that as the tumor diameter increased and there was an exponential increase of the absorbed radiation dose to the tumor, the high doses of radiation to the cell surface led to the focal stimulation of tumor necrosis factor- $\alpha$ expression [13] and a high influx of calcium [14], which induced necrosis instead of apoptosis. ${ }^{18} \mathrm{~F}-\mathrm{FDG}$ at the $2-4 \mathrm{mCi}$ doses that were used for the therapy of tumor-bearing animals contained $0.001-0.002 \mathrm{mg}$ of unlabelled FDG, which should not cause any pharmacological effect because the level of glucose in the blood at fasting is $0.7 \mathrm{mg} / \mathrm{ml}(70 \mathrm{mg} / \mathrm{dl})$.

A retrospective study of five patients with metastatic in the tumors $(2.7 \pm 0.8)$. In patients with multiple tumors the SUVs varied from site to site. The tumors with greater uptake of the non-metabolite are affected more than the tumors with less uptake during positron therapy. The SUV of small tumors might suffer from volume averaging in measurement, and these tumors might actually receive a higher dose to the tumor than was measured. The doselimiting organ for ${ }^{18} \mathrm{~F}-\mathrm{FDG}$ administration is the red marrow. Other normal tissues show high ${ }^{18} \mathrm{~F}-\mathrm{FDG}$ uptake, but they are relatively radioresistant. There are methods to reduce uptake by normal tissue. Uptake by cardiac and skeletal muscle is routinely reduced by fasting, and uptake by skeletal muscle can be further reduced with benzodiazepine therapy [15]. Uptake by brain is impossible to avoid. With an administered dose of $7.14 \mathrm{Ci}$ of ${ }^{8} \mathrm{~F}$-FDG, the dose to the brain is $570 \mathrm{rad}$. In external beam brain radiation therapy, $5040 \mathrm{rad}$ is given in 28 fractions of $180 \mathrm{rad}$ each, accompanied by corticosteroid therapy to decrease brain inflammation and edema [16]. The ${ }^{18}$ F-FDG therapy dose can be also be fractionated and corticosteroids can be administered to prevent toxicity to the brain. The dose to the bladder and kidneys can be reduced with a Foley catheter and diuretic administration [17]. These data suggest that ${ }^{18} \mathrm{~F}-\mathrm{FDG}$ therapy can be used safely in ${ }^{18} \mathrm{~F}$-FDG-avid malignancies.

With regard to long-term toxicity from positron therapy, it has been shown that after large cumulative doses of ${ }^{131}$ I for metastatic thyroid cancer, the risk of secondary leukemia is 0.4 deaths per $10^{4}$ patient-year-grays [18]. We would expect patients with metastatic breast cancer treated with high doses of FDG to have a similar risk for latent leukemia. Patients who require whole-brain radiation therapy generally do not live long enough to attain a secondary malignancy, and there are no data on this.

One other possible advantage of using ${ }^{18} \mathrm{~F}-\mathrm{FDG}$ as a therapeutic agent in breast cancer is that up to $29 \%$ of glucose utilization in the tumor is due to uptake in nonneoplastic cells, mostly macrophages [19]. In a mouse model it has been shown that macrophages contribute to tumor progression and metastasis [20]. Thus, treatment with ${ }^{18} \mathrm{~F}$-FDG of metastatic breast cancer with poor prognosis could be particularly suitable because the macrophages are targeted in addition to the tumor cells.

We can envisage the application of other positron-emitters that have longer half-lives and emit higher-energy positrons than those emitted by ${ }^{18} \mathrm{~F}$ for positron tumor therapy. For example, ${ }^{76} \mathrm{Br}$-labeled bromo-D-glucose [21] could potentially deliver a higher radiation dose to the tumor because ${ }^{76} \mathrm{Br}$ has a longer half-life (16.2 hours) than ${ }^{18} \mathrm{~F}$ and emits positrons with an energy of $3.44 \mathrm{MeV}$. Other compounds of interest for positron tumor therapy might include ${ }^{124}$-labeled iododeoxyuridine (half-life 4.2 days, energy $2.13 \mathrm{MeV}$ ), which incorporates into the DNA of 
cancer cells, and ${ }^{64} \mathrm{Cu}$-pyruvaldehyde bis(N-methylthiosemicarbazone) (half-life 12.7 hours, energy $0.657 \mathrm{MeV}$ ) for the treatment of hypoxic tumors.

\section{Conclusion}

We have shown, to our knowledge for the first time, that positrons delivered by $18 \mathrm{~F}-\mathrm{FDG}$ to mammary tumors in mice cause apoptosis and necrosis of breast cancer cells. The dosimetry of ${ }^{18} \mathrm{~F}-\mathrm{FDG}$ for tumors and normal organs in breast cancer patients suggests that ${ }^{18} \mathrm{~F}-\mathrm{FDG}$ is a candidate for the radiomolecular therapy of refractory breast cancer and other cancers.

\section{Competing interests}

None declared.

\section{Acknowledgements}

The research was supported by Albert Einstein College of Medicine grant 9526-9593 (to ED) and by $\mathrm{NCl}$ grant $\mathrm{P} 30 \mathrm{CA013330-319017}$ (to JWP).

\section{References}

1. Di Chiro G, De La Paz RL, Brooks RA, Sokoloff L, Kornblith PL, Smith BH, Patronas NJ, Kufta CV, Kessler RM, Johnston GS, Manning RG, Wolf AP: Glucose utilization of cerebral gliomas measured by [ $\left.{ }^{18} \mathrm{~F}\right]$ fluorodeoxyglucose and positron emission tomography. Neurology 1982, 32:1323-1329.

2. Hustinx R, Benard F, Alavi A: Whole-body FDG-PET imaging in the management of patients with cancer. Semin Nucl Med 2002, 32:35-46.

3. Warburg O: The Metabolism of Tumors. London: Arnold Constable; 1930.

4. Bombardieri E, Crippa F: PET imaging in breast cancer. Q $J$ Nucl Med 2001, 45:245-256.

5. Gallagher BM, Fowler JS, Gutterson NI, McGregor RR, Wan CN, Wolf AP: Metabolic trapping as a principal of radiopharmaceutical design: some factors responsible for biodistribution of ${ }^{18} \mathrm{~F}$ 2-deoxy-2-fluoro-D-glucose. J Nucl Med 1978, 19:1154-1161.

6. Seidlin SM, Marinelli LD, Oshry E: Radioactive iodine therapy. JAMA 1946, 132:838-847.

7. Muller WJ, Sinn E, Pattengale PK, Wallace R, Leder P: Singlestep induction of mammary adenocarcinoma in transgenic mice bearing the activated c-neu oncogene. Cell 1988, 54: 105-115.

8. Gouon-Evans V, Rothenberg ME, Pollard JW: Postnatal mammary gland development requires macrophages and eosinophils. Development 2000, 127:2269-2282.

9. Early PJ, Sodee BD: Principles and Practice of Nuclear Medicine. St Louis: Mosby; 1995.

10. Stoll HP, Hutchins GD, Winkle WL, Nguyen AT, Appledorn CR, Janzen I, Seifert H, Rube C, Schieffer H, March KL: Advantages of short-lived positron-emitting radioisotopes for intracoronary radiation therapy with liquid-filled balloons to prevent restenosis. J Nucl Med 2001, 42:1375-1383.

11. MacKeehan WL: Glycolysis, glutaminolysis and cell proliferation. Cell Biol Int Rep 1982, 6:635-650.

12. Knox SJ, Goris ML, Wessels BW: Overview of animal studies comparing radioimmunotherapy with dose equivalent external beam radiation. Radiother Oncol 1992, 23:111-117.

13. Gupta VK, Park JO, Jaskowiak NT, Mauceri HJ, Seetharam S Weichselbaum RR, Posner MC: Combined gene therapy and ionizing radiation is a novel approach to treat human esophageal adenocarcinoma. Ann Surg Oncol 2002, 9:500504.

14. Cornelissen M, Thierens H, De Ridder L: Interphase death in human peripheral blood lymphocytes after moderate and high doses of low and high LET radiation: an electron microscopic approach. Anticancer Res 2002, 22:241-245.

15. Barrington SF, Maisey MN: Skeletal muscle uptake of fluorine-18FDG: effect of oral diazepam. J Nucl Med 1996, 37:1127-1129.
16. Patchell RA, Tibbs PA, Regine WF, Dempsey RJ, Mohiuddin M, Kryscio RJ, Markesbery WR, Foon KA, Young B: Postoperative radiotherapy in the treatment of single metastasis to the brain: a randomized trial. JAMA 1998, 280:1485-1489.

17. Moran JK, Lee HB, Blaufox MD: Optimization of urinary FDG excretion during PET imaging. J Nucl Med 1999, 40:13521357.

18. Edmonds CJ, Smith T: The long-term hazards of the treatment of thyroid cancer with radioiodine. Br J Radiol 1986, 59:45-51.

19. Kubota R, Yamada S, Kubota K, Ishiwata K, Tamahashi N, Ido T: Intratumoral distribution of fluorine-18-fluorodeoxyglucose in vivo: high accumulation in macrophages and granulation tissues studies by microautoradiography. J Nucl Med 1992, 33:1972-1980.

20. Lin EY, Nguyen AV, Russell RG, Pollard JW: Colony-stimulating factor 1 promotes progression of mammary tumors to malignancy. J Exp Med 2001, 193:727-739.

21. Pagani M, Stone-Elander S, Larsson SA: Alternative positron emission tomography with non-conventional positron emitters: effect of their physical properties on image quality and potential clinical applications. Eur J Nucl Med 1997, 24:13011327.

\section{Correspondence}

Ekaterina Dadachova PhD, Albert Einstein College of Medicine, Department of Nuclear Medicine, 1695A Eastchester Road, Bronx, NY 10461, USA. Tel: +1 718405 8485; fax: +1 718405 8457; e-mail: edadacho@aecom.yu.edu 